\title{
Unknown syndrome: nasal hypoplasia, sparse hair, truncal obesity, genital hypoplasia, and severe mental retardation
}

Jean-Pierre Fryns, Jessica Delooz, Herman Van Den Berghe

\begin{abstract}
A 4 year old girl is described with severe mental retardation, peculiar face with nasal hypoplasia, sparse hair, genital hypoplasia, truncal obesity, puffy hands, and small feet with complete cutaneous syndactyly of the second and third toes. ( $f$ Med Genet 1992;29:676-7)
\end{abstract}

\section{History}

The proband was a 4 year old girl, born at term after a normal pregnancy. She was the only child of healthy, unrelated parents. At her birth the mother was 39 and the father 42 years old. Both parents had two normal children from a first marriage. Family history was negative. Birth weight was $3300 \mathrm{~g}$ and length $50 \mathrm{~cm}$. Immediately after birth the distinct facial appearance, complete cutaneous syndactyly of toes 2 and 3, and generalised hypotonia were noted. Subluxation of the right hip was treated with an abduction apparatus. At the age of 2 months a vertical nystagmus was noted. Ophthalmologic examination and electroretinography were normal. This nystagmus regressed steadily and had disappeared by the age of 1.5 years. Motor development was severely retarded. She started to crawl at the age of 2.5 years and walked without support after her third year. Verbal and motor training were started at the age of 2 years. At the age of 3.5 years psychological testing (BOS 2-30) showed severe mental retardation (mental age 14 to 15 months, motor age 14 months).

\section{Clinical examination}

On several clinical evaluations between the ages of 3.5 and 4 years the child was severely mentally delayed but friendly and socially interested. Her height was $106 \mathrm{~cm}$ (75th to 90th centile), weight $21 \mathrm{~kg}$ (97th centile), and head circumference $52 \mathrm{~cm}$ (90th centile). The cranium was narrow with a high forehead and temporal flattening. The hair was fine and thin, the eyebrows sparse, and there was ptosis, hypertelorism, and bilateral epicanthus. The nose was small with hypoplastic alae and a short columella, the philtrum was long, and the upper lip thin (figs 1 and 2). The palate was high arched and the teeth were small with hypoplastic enamel. There was persisting hypotonia, truncal obesity, widely spaced nipples, and hypoplastic labia majora and minora. The hands and feet were small with puffy

\author{
Centre for Human \\ Genetics, University \\ 49, 3000 Leuven. \\ Belgium. \\ J-P Fryns \\ $\mathrm{H}$ Van Den Berghe \\ Correspondence to \\ Professor Fryns \\ Received 26 November \\ 1991. \\ Revised version accepted \\ 15 January 1992
}

Figure 1 The distinct facial appearance with nasal

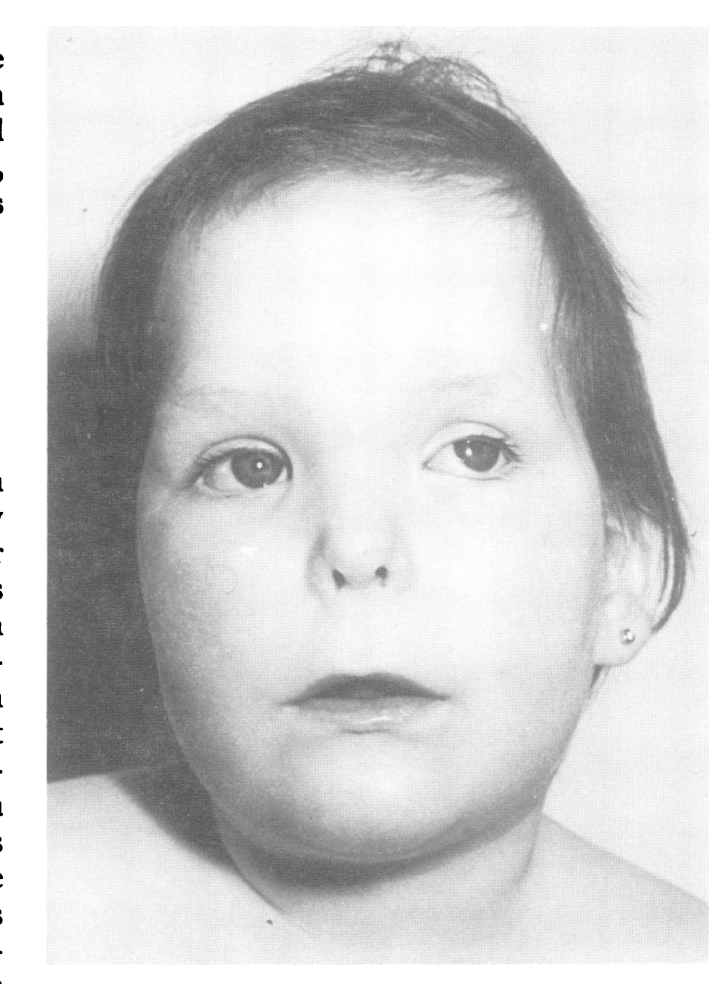

\section{hypoplasia.}

Figure 2 General habitus with hypotonia, truncal obesity, and smal hands and feet. 
fingers and bilateral complete cutaneous syndactyly of toes 2 and 3. Nails and sweating were normal, and no abnormalities in skin pigmentation were noted.

\section{Investigations}

Routine haematology, blood chemistry, and metabolic screening gave normal results. Chromosomal analysis showed a normal female karyotype (GTG banding, approximately 850 bands). Radiographic survey of the skeleton was unremarkable except for a diffuse osteoporosis of the hands, feet, and long bones. The CT scan of the brain was normal.

\section{Discussion}

In this patient severe retardation was associated with peculiar facial features with marked nasal hypoplasia, hypotrichosis, small external genitalia, truncal obesity with contrasting small, puffy hands and feet, and complete cutaneous syndactyly of toes 2 and 3 . Hypotonia was noted from the neonatal period, but regressed progressively and the child started to walk after the age of 3 years. The diagnosis of Laurence-Moon-Biedl syndrome ${ }^{1}$ was considered, but retinitis pigmentosa was excluded after electroretinography. Moreover, the distinct facial stigmata with nasal hypoplasia are not seen in this syndrome nor in Cohen syndrome $^{2}$ in which the nasal bridge is high with contrasting maxillar hypoplasia, open mouth, and prominent incisors.

We could not find any previous report on the association of severe mental delay, nasal hypoplasia, and the other symptoms present in this girl. ${ }^{3}$ With regard to the aetiology, the raised parental age is in favour of a new dominant mutation or a small, undetected chromosomal rearrangement.

1 Farag TI, Teebi AJ. Bardet-Biedl and Laurence-Moon syndromes in a mixed Arab population. Clin Genet 1988;33:78-82.

2 Young ID, Moore JP. Intrafamilial variation in Cohen syndrome. F Med Genet 1987;24:488-92.

3 Winter R, Baraitser N. Multiple congenital anomalies. A diagnostic compendum. London: Chapman and Hall Medical, 1991. 